\section{The benefits of influenza vaccine in pregnancy for the fetus and the infant younger than six months of age}

\author{
Noni E MacDonald, Jane C McDonald; Canadian Paediatric Society, Infectious \\ Diseases and Immunization Committee
}

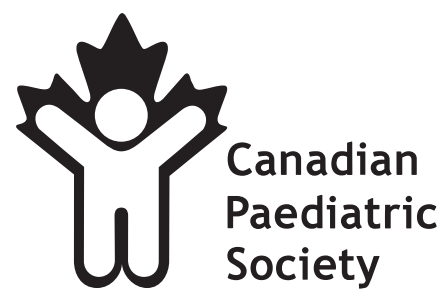

Français en page e 123

\begin{abstract}
NE MacDonald, JC McDonald. The benefits of influenza vaccine in pregnancy for the fetus and the infant younger than six months of age. Paediatr Child Health 2014;19(9):e121. e122.

Influenza is a serious problem for infants $<6$ months of age, whose hospitalization rates for influenza and associated illness are comparable with rates in the elderly. Because influenza vaccines are not effective in this age group, the optimal evidence-based strategy is to administer trivalent inactivated influenza vaccines during pregnancy. Immunizing with trivalent inactivated influenza vaccines in the second and third trimester is well studied and safe, not only providing protection for the pregnant woman and her infant $<6$ months of age, but also for the fetus by decreasing the risk for low birth weight.
\end{abstract}

Key Words: ALRI; Cocooning; Influenza; TIV

$\mathrm{T}$ he global influenza disease burden in children $<5$ years of age is substantial, with an estimated 90 million cases in 2008 , 20 million with acute lower respiratory illness and 28,000 to 111,500 deaths.(1) Even in industrialized countries, influenza remains a significant cause of hospitalization, emergency room visits and outpatient visits in this age group. Infants $<6$ months of age have the highest rate of influenza-attributable hospitalizations in any paediatric age group, $(2)$ with estimates that range from nine to 104 per 10,000 infants $<6$ months of age,(3) comparable with rates observed in adults $>80$ years of age.

For infants and children $\geq 6$ months of age, the trivalent inactivated influenza vaccines (TIV) have been shown to be a safe and effective means of decreasing risk for severe illness with influenza. $(4,5)$ However, preventing influenza in children at highest risk for severe disease, particularly infants $<6$ month of age, is more problematic. Beyond practicing meticulous hand hygiene during influenza season and avoiding contact with infected people, different immunization strategies have been assessed.

Influenza vaccines are not licensed or recommended for infants $<6$ months of age(4) because their immune response, when studied, has been variable and vaccine effectiveness is unclear.(6) Two other immunization strategies to protect the very young have been evaluated: 'cocooning' (the immunization of postpartum women and an infant's household contacts); and immunizing pregnant women.

Cocooning programs have met with some success and evidence suggests that the maternal immunization component provides most of an infant's protection from influenza.(7) However, while the strategy works moderately well in research studies and some clinical settings, the programs are costly and have proven difficult
Les avantages d'administrer le vaccin antigrippal pendant la grossesse pour le foetus et le nourrisson de moins de six mois

La grippe est un grave problème pour les nourrissons de moins de six mois. Chez ces nourrissons, le taux d'hospitalisation attribuable à cette maladie et à des maladies connexes est comparable à celui des personnes âgées. Puisque les vaccins antigrippaux ne sont pas efficaces dans ce groupe d'âge, la stratégie optimale, fondée sur des données probantes, consiste à administrer les vaccins trivalents inactivés pendant la grossesse. L'administration de ces vaccins au cours des deuxième et troisième trimestres a fait l'objet d'études approfondies et est sécuritaire. Non seulement protège-t-elle la femme enceinte et son nourrisson de moins de six mois, mais elle est également bénéfique pour le fotus. En effet, ce vaccin contribue à réduire le risque de faible poids à la naissance.

to implement on a large scale.(8) Furthermore, they are not cost effective in preventing pertussis deaths in infants $<6$ months of age,(9) and are, therefore, unlikely to be cost effective in preventing influenza deaths in same age group.

By contrast, the strategy of immunizing pregnant women during their second or third trimester has been shown in both randomized controlled trials and in population studies to be clinically effective, $(10,11)$ safe $(11,12)$ and cost effective, with decreased hospitalization rates for both mothers and young infants during influenza season. $(13,14)$ Beyond lower maternal and infant influenza-related hospitalization rates, a review of studies investigating antenatal influenza immunization in the second and third trimester, including Canadian studies, has shown reduced frequencies of both preterm and small-for-gestational age (growthrestricted) newborns, albeit with wide variation in effect.(15-17)

Influenza immunization in early pregnancy may be of even greater value. A 2014 systematic review and meta-analysis of the impact of influenza in the first trimester showed higher risk for congenital anomalies, notably neural tube defects, hydrocephaly, congenital heart defects (eg, aortic valve atresia or stenosis and ventricular septal defect), as well as cleft lip, and digestive system and limb reduction defects.(18) Such teratogenic effects may be a consequence of fever and/or other host responses to influenza infection. Potentially, first-trimester influenza immunization could avert some congenital anomalies. The National Advisory Committee on Immunization recommends immunization with TIV for women in any stage of pregnancy.(19) This recommendation is supported by the Society of Obstetricians and Gynecologists of Canada: http://sogc.org/publications/immunization-before-andduring-pregnancy/. However, because uptake is far from universal, 
greater efforts are needed both to encourage health care workers to offer influenza vaccine to pregnant women and for women to accept. If the vaccine was not given during pregnancy, mothers of young infants should be immunized to decrease the risk for influenza and, if breastfeeding, the infant receives further protection from the passive transfer of antibodies in breast milk.(20)

In summary, to prevent influenza in infants $<6$ months of age, the best evidence-based strategy is to administer influenza vaccines during pregnancy. Immunization with TIV in the second and third trimester is well studied, safe and has protective effects for both mother and child before birth. Furthermore, the infant is born with influenza antibodies, which offer some protection until the first dose of influenza vaccine can be given at six months of

\section{REFERENCES}

1. Nair H, Brooks WA, Katz M, et al. Global burden of respiratory infections due to seasonal influenza in young children: A systematic review and meta-analysis. Lancet 2011;378(9807):1917-30.

2. Neuzil KM, Mellen BG, Wright PF, Mitchel EF Jr, Griffin MR. The effect of influenza on hospitalizations, outpatient visits and courses of antibiotics in children. N Engl J Med 2000;342(4):225-31.

3. Poehling KA, Edwards KM, Griffin MR, et al. The burden of influenza in young children, 2004-2009. Pediatrics 2013;131(2):207-16.

4. Public Health Agency of Canada, National Advisory Committee on Immunization (NACI). Statement on seasonal influenza vaccine for 2013-14. Canada Communicable Disease Report CCDR. October 2013; 39(ACS-4): www.phac-aspc.gc.ca/publicat/ccdr-rmtc/13vol39/ acs-dcc-4/index-eng.php (Accessed October 6, 2014).

5. SAGE Working Group. Background paper on influenza vaccines and immunization: www.who.int/immunization/sage/meetings/2012/ april/1_Background_Paper_Mar26_v13_cleaned.pdf (Accessed October 6, 2014).

6. Walter EB, Englund JA, Blatter M, et al; GRC27 Study Team. Trivalent inactivated influenza virus vaccine given to two-month-old children: An off-season pilot study. Pediatr Infect Dis J 2009;28(12):1099-104.

7. Maltezou HC, Fotiou A, Antonakopoulos N, et al. Impact of postpartum influenza vaccination of mothers and household contacts in preventing febrile episodes, influenza-like illness, healthcare seeking, and administration of antibiotics in young infants during the 2012-2013 influenza season. Clin Infect Dis 2013;57(11):1520-6.

8. Guzman-Cottrill JA, Phillipi CA, Dolan SA, Nyquist AC, Win A, Siegel J. Free vaccine programs to cocoon high-risk infants and children against influenza and pertussis. Am J Infect Control 2012;40(9):872-6.

9. Skowronski DM, Janjua NZ, Tsafack EP, Ouakki M, Hoang L, De Serres $G$. The number needed to vaccinate to prevent infant pertussis hospitalization and death through parent cocoon immunization. Clin Infect Dis 2012;54(3):318-27.

10. Steinhoff MC, Omer SB. A review of fetal and infant protection associated with antenatal influenza immunization. Am J Obstet Gynecol 2012;207(3 Suppl):S21-7. age. In temperate climates where influenza is seasonal, maternal immunization should be performed before influenza season starts. While appropriate hand hygiene by everyone in contact with infants during influenza season and avoiding contact between infants and infected people can help to prevent illness, immunization in pregnancy is a key step to protecting an especially vulnerable group in their first months of life.

ACKNOWLEDGEMENTS: This practice point was reviewed by the Fetus and Newborn Committee of the Canadian Paediatric Society, as well as by representatives from the Society of Obstetricians and Gynecologists of Canada and the College of Family Physicians of Canada.

11. Madhi SA, Cutland CL, Kuwanda L, et al; Maternal Flu Trial (Matflu) Team. Influenza vaccination of pregnant women and protection of their infants. N Engl J Med 2014;371(10):918-31.

12. Tamma PD, Ault KA, del Rio C, Steinhoff MC, Halsey NA, Omer SB. Safety of influenza vaccination during pregnancy. Am J Obstet Gynecol 2009;201(6):547-52.

13. Beigi RH, Wiringa AE, Bailey RR, Assi TM, Lee BY. Economic value of seasonal and pandemic influenza vaccination during pregnancy. Clin Infect Dis 2009;49(12):1784-92.

14. Skedgel C, Langley JM, MacDonald NE, Scott J, McNeil S. An incremental economic evaluation of targeted and universal influenza vaccination in pregnant women. Can J Public Health 2011;102(6):445-50.

15. Fell DB, Dodds L, MacDonald NE, Allen VM, McNeil S. Influenza vaccination and fetal and neonatal outcomes.Expert Rev Vaccines 2013;12(12):1417-30.

16. Legge A, Dodds L, Maconald NE, Scott J, McNeil S. Rates and determinants of seasonal influenza vaccination in pregnancy and association with neonatal outcomes. CMAJ 2014;186(4):E157-64.

17. Fell DB, Sprague AE, Liu N, et al; Better Outcomes Registry and Network (BORN) Ontario. H1N1 influenza vaccination during pregnancy and fetal and neonatal outcomes. Am J Public Health 2012;102(6):e33-40.

18. Luteijn JM, Brown MJ, Dolk H. Influenza and congenital anomalies: A systematic review and meta-analysis. Hum Reprod 2014;29(4):809-23.

19. Public Health Agency of Canada, National Advisory Committee on Immunization. Statement on seasonal influenza vaccine for 2014-2015: http://publications.gc.ca/collections/collection_2014/ aspc-phac/HP40-114-2014-eng.pdf (Accessed October 6, 2014).

20. Maertens K, De Schutter S, Braeckman T, et al. Breastfeeding after maternal immunisation during pregnancy: Providing immunological protection to the newborn; A review. Vaccine 2014;32(16):1786-92.

\section{CPS INFECTIOUS DISEASES AND IMMUNIZATION COMMITTEE}

Members: Natalie A Bridger MD; Jane C Finlay MD (past member); Susanna Martin MD (Board Representative); Jane C McDonald MD; Heather Onyett MD; Joan L Robinson MD (Chair); Marina I Salvadori MD (past member); Otto G Vanderkooi MD

Liaisons: Upton D Allen MBBS, Canadian Pediatric AIDS Research Group; Michael Brady MD, Committee on Infectious Diseases, American Academy of Pediatrics; Charles PS Hui MD, Committee to Advise on Tropical Medicine and Travel (CATMAT), Public Health Agency of Canada; Nicole Le Saux MD, Immunization Monitoring Program, ACTive (IMPACT); Dorothy L Moore MD, National Advisory Committee on Immunization (NACI); Nancy Scott-Thomas MD, College of Family Physicians of Canada; John S Spika MD, Public Health Agency of Canada

Consultant: Noni E MacDonald MD

Principal authors: Noni E MacDonald MD, Jane C McDonald MD

The recommendations in this document do not indicate an exclusive course of treatment or procedure to be followed. Variations, taking into account individual circumstances, may be appropriate. All Canadian Paediatric Society position statements and practice points are reviewed on a regular basis. Retired statements are removed from the website. Please consult the Position Statements section of the CPS website (www.cps.ca) for the full-text, current version. 